\title{
Taxa de câmbio e indústria de transformação no Brasil: Evidências para o período 1980-2008
}

\author{
Eliane Araújo* \\ Miguel Bruno** \\ Débora Pimentel $^{* * *}$
}

\begin{abstract}
RESUMO - Este artigo propõe uma análise das relações entre taxa de câmbio e evolução da indústria de transformação brasileira no período 1980-2008. Seu principal objetivo é detectar o sentido das transformações estruturais impostas pela nova forma de inserção internacional consolidada ao longo da década de 1990. O trabalho proporciona ainda novas evidências empíricas quanto às hipóteses de desindustrialização e de "doença holandesa", que marcam o debate atual sobre os efeitos da apreciação real do câmbio sobre a economia.
\end{abstract}

Palavras chaves: Taxa de câmbio. Indústria. Mudanças estruturais.

\section{INTRODUÇÃO}

Diversos trabalhos empíricos têm procurado detectar os impactos das estratégias nacionais de liberalização econômica sobre as estruturas de produção industrial. Nessa problemática, as mudanças de regimes cambiais, entendidos como o conjunto de normas que regem a administração da taxa de câmbio, têm se constituído em um ponto de partida natural para uma análise robusta das transformações da indústria, quando o grau de abertura comercial e financeira é significativamente aprofundado. No entanto, diferentemente do que ocorre no âmbito internacional, a literatura econômica para o caso do Brasil ainda carece de estudos sobre os efeitos das taxas de câmbio sobre o comportamento da indústria.

Apesar do discurso corrente acerca das características supostas quase sempre positivas de uma economia baseada em serviços, consagrando o uso de expressões tais como “economia do conhecimento", “economia pós-industrial” e "nova economia”, a experiência histórica mostra que a indústria ainda é a base do desenvolvimento das nações. Mesmo que

\footnotetext{
* Doutora em Economia. Universidade Federal do Rio de Janeiro, UFRJ, Brasil. Pesquisadora da coordenação de crescimento e desenvolvimento econômico IPEA. Endereço eletrônico: eliane.araujo@ipea.gov.br.

** Doutora em Economia das Instituições. École des Hautes Études en Sciences Sociales, EHESS, França. Assessor de projetos especiais - crescimento e desenvolvimento do IPEA e professor adjunto da UERJ. Endereço eletrônico: miguel.bruno@ipea.gov.br.

*** Mestranda em Economia. Escola nacional de Ciências Estatísticas, ENCE-IBGE, Brasil. Endereço eletrônico: deboramp@globo.com.
} 
nas atuais economias os serviços tenham alcançado posições qualitativa e quantitativamente proeminentes, a indústria continua sendo a principal fornecedora dos insumos fundamentais às atividades terciárias. $\mathrm{O}$ deslocamento do emprego industrial pelo emprego terciário não implica necessariamente em perda de importância econômica do setor secundário, visto que a geração de valor nos serviços permanece substancialmente dependente da materialização de conceitos, de inovações tecnológicas e das infra-estruturas provenientes de processos produtivos industriais. Reforçando essa tendência de subavaliação da relevância da indústria pode-se acrescentar o fato de que inúmeras atividades que outrora eram consideradas tipicamente industriais têm sido reclassificadas e introduzidas no rol dos serviços, tendo-se em vista os benefícios fiscais e organizacionais dos processos de terceirização.

Este artigo propõe uma análise das relações entre taxa de câmbio e desempenho da indústria de transformação brasileira no período 1980-2008. Seu principal objetivo é detectar o sentido das transformações impostas pela nova forma de inserção internacional consolidada ao longo da década de 1990. O trabalho proporciona novas evidências empíricas quanto às hipóteses de desindustrialização e de "doença holandesa" que marcam o debate atual sobre os efeitos da apreciação real do câmbio sobre a economia.

Além desta introdução, o texto está estruturado da seguinte maneira: Com base em séries do valor agregado da indústria de transformação e da taxa efetiva real de câmbio, apresenta-se um fato estilizado da evolução contemporânea da indústria, por expressar, no plano macroeconômico, mutações importantes na configuração deste setor. A próxima seção reúne evidências sobre a nova estrutura industrial pós-liberalização, explicitando o novo padrão de especialização em nível setorial. A seção 4 apresenta os efeitos desta especialização para o comércio exterior brasileiro. O trabalho é concluído com a seção 5 .

\section{FATO ESTILIZADO: FORTE DA QUEDA DA PARTICIPAÇÃO DO VALOR AGREGADO NO PIB}

O gráfico 1 mostra as evoluções conjuntas da participação da indústria de transformação no produto total da economia brasileira (valor adicionado industrial / PIB a preços básicos) e da taxa de câmbio efetiva real, em índices dos valores. Pode-se constatar a existência de dois diferentes padrões de evolução das séries e também o fato de a apreciação 
cambial estar associada a uma perda de mais de 50\% da participação do valor adicionado industrial, no período 1980-1998. ${ }^{1}$

Observe-se que a queda relativa do VA industrial tem início no período pré-abertura, quando, paralelamente, a taxa de crescimento da indústria não pode ser atribuída ao processo normal de desenvolvimento econômico, onde, no longo prazo, o setor serviços avança com conseqüente redução da participação relativa do setor industrial e agrícola. Até o ano de 1993, a participação relativa da indústria de transformação e a taxa de câmbio compartilhavam uma tendência comum de evolução, sugerindo a possibilidade de essas séries serem cointegradas. ${ }^{2}$ A partir de 1994, essas variáveis se desconectam, exibindo outro padrão muito diferente de evolução onde a participação do VA da indústria no PIB se mostra muito pouco sensível ao regime cambial vigente. Além disso, deve ser destacado que, no segundo período 1994-2007, caracterizado pela liberalização comercial e financeira e pelas transformações estruturais subseqüentes, esta participação representa apenas metade do valor observado em 1980. Um sinal que aponta para a ocorrência de um processo de "desindustrialização relativa" da economia brasileira pós-abertura e pós-Real.

GRÁFICO 1 - TAXA DE CÂMBIO EFETIVA REAL E PARTICIPAÇÃO DA INDÚSTRIA DE TRANSFORMAÇÃO NO PIB

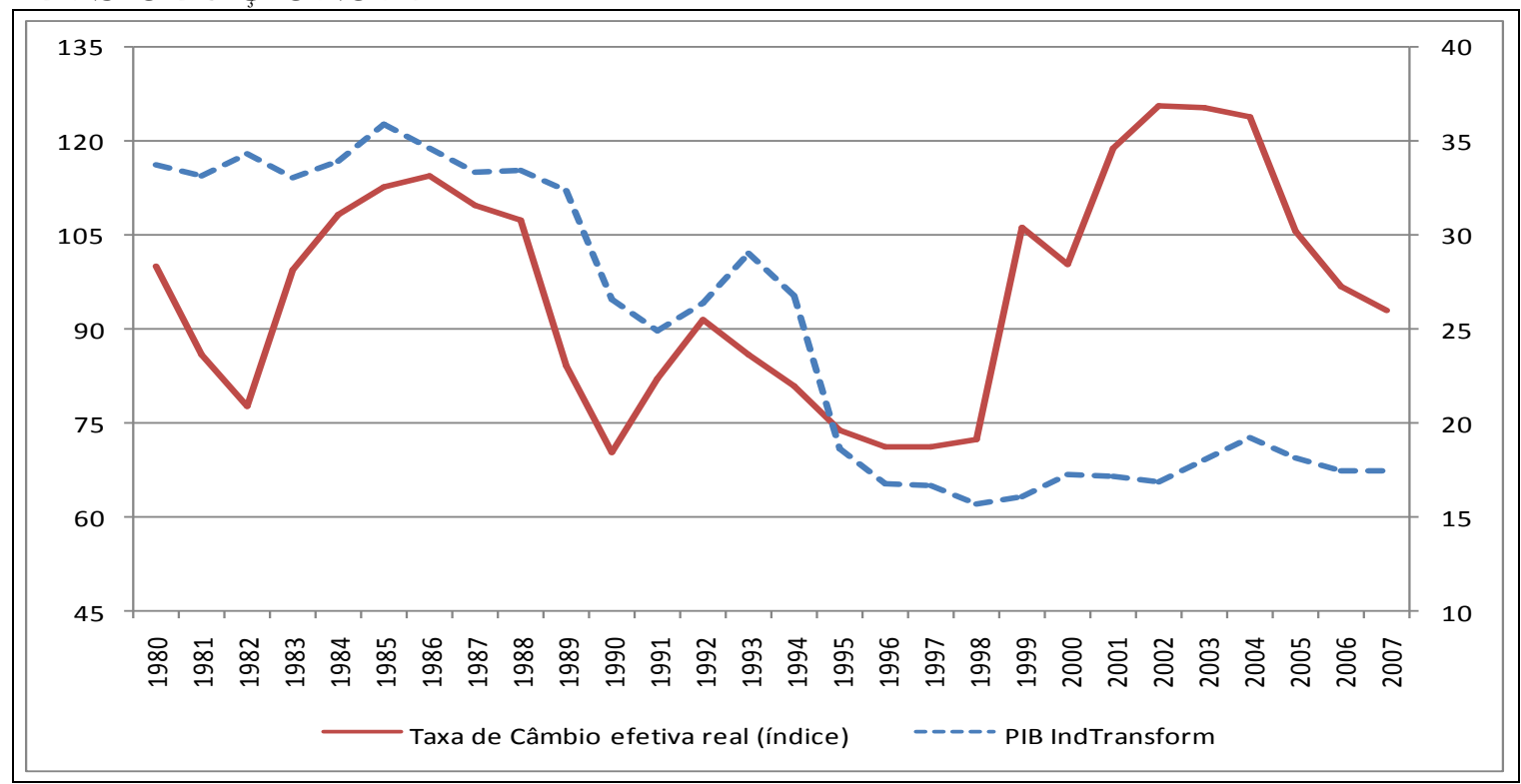

FONTE: IPEADATA (2009).

Uma possível explicação pode ser obtida considerando-se a ocorrência de mudanças estruturais na indústria, desencadeadas pela nova forma de inserção internacional da

\footnotetext{
${ }^{1}$ Precisamente, uma queda de 53,37\%.

${ }^{2}$ Em Araújo, Bruno e Pimentel (2009) são apresentados testes econométricos que confirmam a existência de cointegração entre as séries de 1980 a 1993 e uma quebra estrutural na relação entre taxa de câmbio e VA industrial no ano de 1993.
} 
economia brasileira. No período 1980-1993, a configuração da indústria de transformação ainda refletia as estruturas de produção consolidadas ao longo do processo de substituição de importações e, portanto, do modelo econômico e das políticas de desenvolvimento industrial correspondentes. O regime cambial, combinado com políticas setoriais, fora mobilizado como uma das instituições-chave para a formação de capacidade produtiva no setor industrial. ${ }^{3} \mathrm{~A}$ indústria era composta por ramos que se constituíram sob a lógica e as incitações econômicas do modelo de industrialização por substituição de importações (MISI). Na vigência deste modelo, uma taxa de câmbio competitiva ou suficientemente depreciada garantia um ambiente macroeconômico favorável aos investimentos industriais.

Mas na passagem para o segundo período, 1994-2008, a nova forma de inserção internacional do Brasil foi marcada por um processo acelerado de liberalização comercial e financeira, conjugado com uma forte apreciação da taxa de câmbio real. A opção brasileira por uma nova forma de adesão ao regime internacional sem uma política industrial consistente vai acarretar transformações profundas no parque industrial, deslocando parte significativa dos ramos que produziam bens com maior intensidade tecnológica e valor agregado. Tais ramos certamente teriam contribuído para reduzir a elevada participação das commodities na pauta de exportações e, portanto, para reduzir a vulnerabilidade externa da economia brasileira em sua fase de adesão ao processo de globalização.

Esse novo ambiente macroeconômico pós-abertura foi determinante para a retração ou o fechamento de diversas unidades produtivas industriais que se viram rapidamente expostas à concorrência internacional, sem o intercurso de uma política de desenvolvimento industrial consistente e adequada às necessidades do crescimento e do desenvolvimento econômico nacional. A hipótese sustentada por este trabalho é a de que o regime de câmbio apreciado foi prejudicial aos setores e ramos tecnologicamente mais sofisticados, favorecendo os ramos mais tradicionais e os ligados às atividades primárias. Esse regime mudou o perfil de especialização da indústria, provocando um processo de "desindustrialização relativa" da economia brasileira.

Neste caso, a indústria perde sua participação econômica antes mesmo de a economia ter alcançado seus estágios mais avançados de desenvolvimento. Esta desindustrialização tem como contrapartida uma expansão igualmente precoce do setor serviços ("inchaço do terciário") conduzindo, inclusive, à progressiva precariedade do

\footnotetext{
${ }^{3} \mathrm{Na}$ atualidade, o exemplo característico dessa estratégia tem sido o dos países asiáticos que mantêm taxas de câmbio adequadas ao desenvolvimento e consolidação de sua indústria, ver, por exemplo, Araújo (2009).
} 
trabalho e a níveis mais elevados de informalidade, sendo, portanto, um fator de bloqueio do processo de desenvolvimento econômico e social.

Destaque-se que os ramos remanescentes do processo de desindustrialização da economia brasileira pós-liberalização são precisamente aqueles cujo desempenho é pouco afetado pelo atual regime de câmbio flutuante com forte tendência à apreciação. Consequentemente esta característica apontaria para a ocorrência de "doença holandesa". Segundo Pereira (2008), esse fenômeno conexo caracteriza-se pela expansão, em um país, da produção dos setores de bens comercializáveis, beneficiados por alguma vantagem comparativa natural (abundância e maior produtividade de recursos naturais, por exemplo) e o declínio relativo concomitante das atividades manufatureiras. Como sustentam Corden e Neary (1982) e Bresser-Pereira (2008), uma apreciação permanente da taxa de câmbio real deve estar associada a um aumento relativo do setor exportador de commodities, de maior produtividade, e a um encolhimento do setor manufatureiro.

\section{UMA ANÁLISE POR RAMOS DA INDÚSTRIA DE TRANSFORMAÇÃO}

Para analisar as eventuais mudanças ocorridas na estrutura interna da indústria de transformação a partir da liberalização econômica os diversos segmentos de atividades industriais foram classificados de acordo com o tipo de fator intensivo. A tipologia foi elaborada pela OECD inspirada em Pavitt (1984).

De acordo com essa classificação as atividades industriais podem ser agregadas em cinco grupos:

i) Indústria intensiva em recursos naturais: o principal fator competitivo é a existência de uma ampla oferta de recursos naturais no país.

ii) Indústria intensiva em trabalho: o principal fator é a alta disponibilidade de mão de obra com custo reduzido, são caracterizadas também pelo fato que um grau elevado dos processos de inovação tecnológica são exógenos, ou seja, realizado por outros setores.

iii) Indústria intensiva em escala: neste grupo, o fator competitivo é a possibilidade de explorar ganhos de escala, sendo a produção caracterizada por indivisibilidade tecnológica. É formada por grandes empresas oligopolistas com elevada intensidade de capital.

iv) Indústria intensiva em tecnologia diferenciada: caracterizadas por elevada obtenção de economias de escopo, alta diversificação da oferta e alta capacidade de inovação produtiva. 
v) Indústria baseada em ciência: atividades inovadoras com elevados gastos de pesquisa e desenvolvimento, cujo fator competitivo é a rápida aplicação da pesquisa científica às tecnologias industriais, e alto poder de difusão sobre todo o sistema econômico.

Os dados utilizados para classificar as indústrias segundo a metodologia Pavitt (1984) e calcular a participação das atividades industriais em relação à totalidade da indústria de transformação, foram retirados da pesquisa da indústria (PIA) do IBGE (2008). Os dados são divididos em duas séries, a primeira de 1988 a 1995 e a segunda de 1996 a 2005. Devido às mudanças ocorridas na classificação das atividades industriais, com a implementação da CNAE (Classificação Nacional da Atividade Econômica) a partir de 1996 se torna difícil a comparação de algumas atividades entre os dois períodos.

As tabelas 1 e 2 apresentam o Valor da Transformação Industrial (VTI) das indústrias segundo a classificação Pavitt (1984). O VTI é a diferença entre valor bruto da produção industrial e o custo das operações industriais.

TABELA 1 - PARTICIPAÇÃO PERCENTUAL NO VALOR DE TRANSFORMAÇÃO DA INDÚSTRIA 1988 A 1995

\begin{tabular}{l|c|c|c|c|c|c|c}
\hline & \multicolumn{1}{|c|}{$\mathbf{1 9 8 8}$} & $\mathbf{1 9 8 9}$ & $\mathbf{1 9 9 0}$ & \multicolumn{1}{c|}{$\mathbf{1 9 9 2}$} & $\mathbf{1 9 9 3}$ & \multicolumn{1}{c}{$\mathbf{1 9 9 4}$} & \multicolumn{1}{c}{$\mathbf{1 9 9 5}$} \\
\hline Produção em escala & 48.34 & 47.30 & 46.68 & 50.56 & 49.55 & 50.67 & 50.79 \\
Recursos Naturais & 18.36 & 17.77 & 18.35 & 20.73 & 20.25 & 20.88 & 22.47 \\
Trabalho & 13.67 & 14.79 & 15.26 & 11.59 & 12.75 & 12.00 & 10.02 \\
Ciência & 10.34 & 10.83 & 10.88 & 10.04 & 11.06 & 10.23 & 10.73 \\
Diferenciado & 9.28 & 9.30 & 8.83 & 7.07 & 6.39 & 6.21 & 6.00 \\
\hline
\end{tabular}

FONTE: IBGE - Pesquisa Industrial Anual.

NOTA: Participação Percentual somente na indústria de transformação.

Analisando os dados das tabelas, pode-se verificar que as atividades que mais aumentaram a sua participação no valor da transformação industrial (VTI) foram as intensivas em recursos naturais, com um aumento de quase 4 pontos percentuais na primeira série da PIA e de mais de 6 pontos na segunda série. A principal atividade deste grupo é a fabricação de produtos alimentícios, porém a atividade responsável por quase totalidade do crescimento da sua participação foi a ligada ao refino de petróleo.

TABELA 2 - PARTICIPAÇÃO PERCENTUAL NO VALOR DE TRANSFORMAÇÃO DA INDÚSTRIA 1996 A 2005

\begin{tabular}{l|r|r|r|r|r|r|r|r|r|r}
\hline & \multicolumn{1}{|c|}{$\mathbf{1 9 9 6}$} & $\mathbf{1 9 9 7}$ & $\mathbf{1 9 9 8}$ & $\mathbf{1 9 9 9}$ & $\mathbf{2 0 0 0}$ & $\mathbf{2 0 0 1}$ & $\mathbf{2 0 0 2}$ & $\mathbf{2 0 0 3}$ & $\mathbf{2 0 0 4}$ & $\mathbf{2 0 0 5}$ \\
\hline Produção em Escala & 40.34 & 42.08 & 42.26 & 41.30 & 40.25 & 39.13 & 40.20 & 40.97 & 42.68 & 40.44 \\
Recursos Naturais & 30.21 & 29.41 & 29.71 & 32.30 & 33.68 & 33.88 & 34.69 & 36.31 & 34.06 & 36.49 \\
Trabalho & 14.45 & 13.40 & 13.83 & 13.20 & 12.53 & 12.54 & 12.04 & 11.20 & 11.13 & 11.29 \\
Ciência & 4.12 & 3.99 & 3.48 & 3.64 & 4.52 & 4.58 & 3.61 & 2.59 & 3.01 & 2.87 \\
Diferenciado & 10.88 & 11.12 & 10.72 & 9.56 & 9.03 & 9.87 & 9.46 & 8.92 & 9.12 & 8.91 \\
\hline
\end{tabular}

FONTE: IBGE - Pesquisa Industrial Anual.

NOTA: Participação Percentual somente na indústria de transformação. 
As atividades intensivas em escala são as que possuem maior participação no VTI em ambas as séries. Produtos químicos, metalurgia e veículos compõem a grande parte desse grupo que de forma geral manteve estável a sua participação na estrutura da produção industrial.

Os outros três grupos de atividades perderam participação. O grupo intensivo em trabalho foi um dos que apresentou a maior perda de participação, de três pontos percentuais em cada série da PIA, com destaque negativo para a participação do setor têxtil e de vestuário.

O grupo intensivo em produtos diferenciados tem uma queda de participação muito significativa no período. Esse setor é representado pelas atividades de produção de máquinas e equipamentos e sofreu com o forte impacto da abertura comercial e da valorização cambial do período que provocou grande aumento na importação desses itens. Da mesma forma impactou a produção dos setores baseadas em ciência responsáveis pela produção de eletrônicos e de informática.

Portanto, considerando-se os dados apresentados referentes à participação das atividades industriais em relação ao valor da transformação industrial, pode-se constatar que ocorreu no período após a liberalização da economia uma especialização produtiva da indústria com ênfase em setores intensivos em recursos naturais. Enquanto que setores tradicionais como têxteis e vestuário, e atividades ligadas à produção de máquinas e equipamentos perderam importância relativa. Estes setores foram fortemente impactados pelo grande aumento do nível das importações após a abertura comercial.

\section{OS EFEITOS DO CÂMBIO SOBRE O COMÉRCIO EXTERIOR ${ }^{4}$}

Os efeitos do câmbio sobre a indústria têm repercussão direta no comércio exterior brasileiro, tanto sobre o saldo dos diferentes setores exportadores, como sobre a intensidade tecnológica das exportações da indústria brasileira.

É sabido que a composição da balança comercial é o principal indicador de competitividade de uma economia, no entanto, como será mostrado mais adiante, as exportações brasileiras vêm se concentrando em commodities e bens de menor valor agregado. Apesar de o Brasil exportar predominantemente produtos industrializados, seus principais produtos são commodities ou bens de pouca intensidade tecnológica.

\footnotetext{
${ }^{4}$ Os dados desta seção baseiam-se no estudo sobre o comércio exterior realizado pelo Instituto de Estudos para o Desenvolvimento da Indústria (IEDI), 2009.
} 
$\mathrm{Na}$ tabela 3 é possível verificar a dependência do saldo comercial brasileiro (SBC) em relação ao setor de commodities. Os resultados evidenciam a importância da capacidade geradora de saldos comerciais dos setores agrícolas, com destaque para o setor de cereais, produtos animais e agricultura tropical. Quanto aos setores deficitários, destaca-se o setor de química e de máquinas (eletro-eletrônico e demais). Tanto os setores exportadores tradicionais têm mantido sua capacidade de gerar saldos comerciais, como os setores tradicionalmente deficitários mantêm-se dessa maneira e, ainda, estes últimos aumentam sensivelmente sua participação negativa no saldo comercial.

TABELA 3 - SALDO COMERCIAL EM US\$ BILHÕES

\begin{tabular}{lr|r|r|r|r|r} 
& $\mathbf{2 0 0 3}$ & $\mathbf{2 0 0 4}$ & $\mathbf{2 0 0 5}$ & $\mathbf{2 0 0 6}$ & $\mathbf{2 0 0 7}$ & $\mathbf{2 0 0 8}$ \\
\hline Petróleo & -2.0 & -4.6 & -3.7 & -3.1 & -5.1 & -8.2 \\
Mat. primas & 3.0 & 3.8 & 6.4 & 7.8 & 9.2 & 10.5 \\
Prod. florestais & 4.3 & 5.1 & 5.5 & 5.9 & 6.6 & 6.7 \\
Agricultura tropical & 5.4 & 6.2 & 8.4 & 11.2 & 11.2 & 11.7 \\
Produtos animais & 4.3 & 6.4 & 8.3 & 8.6 & 11.4 & 14.8 \\
Cereais & 7.9 & 11.4 & 10.8 & 10.4 & 13.9 & 20.2 \\
Int. em trabalho & 4.1 & 5.0 & 5.7 & 5.8 & 5.4 & 5.7 \\
Int. em capital & 6.1 & 8.1 & 9.8 & 9.5 & 9.0 & 8.7 \\
Maq. Eletro-eletrônic. & -4.1 & -6.5 & -6.8 & -9.1 & -12 & -17.4 \\
Maq. E veículos rodoviários & 3.2 & 4.8 & 6.8 & 6.2 & 4.5 & 1.1 \\
Máq. e outros transportes & 1.4 & 3.6 & 2.6 & 2.2 & 3.9 & 4.2 \\
Máq. Demais & -2.9 & -1.9 & -1.9 & -2.6 & -6.6 & -12.9 \\
Química & -6.1 & -8.1 & -7.3 & -7.2 & -12.2 & -21.4 \\
\hline
\end{tabular}

FONTE: IEDI (2009).

A respeito do desempenho do SBC, o IEDI (2009) chama a atenção para dois aspectos fundamentais. O primeiro deles, é que existe uma crescente relação de antagonismo entre os diferentes segmentos do comércio exterior brasileiro, isto é, existem, por um lado, segmentos claramente superavitários e, por outro, aqueles com resultados extremamente negativos. $\mathrm{O}$ segundo aspecto, que está relacionado ao primeiro, se refere ao fato de que o SBC do país depende cada vez mais de bens de baixo valor agregado, pouco ou nãoindustrializados, cujos empregos gerados exigem baixa qualificação.

O IEDI destaca que este aspecto pode não se configurar como um problema para os defensores da Teoria das Vantagens Comparativas ou correlatas, isto é, da idéia de que cada país deve se especializar nos produtos que possuem menores custos relativos de produção, mas certamente é algo negativo para os que argumentam a favor de um projeto para o Brasil que passa pela industrialização (IEDI, 2009). 
Outro ponto relevante é investigar a intensidade tecnológica dos produtos exportados pela indústria brasileira. ${ }^{5} \mathrm{~A}$ tabela 4 aponta dados do saldo comercial da indústria de transformações no Brasil.

Observa-se que o setor mais importante na geração de saldo comercial para o Brasil, considerando o conteúdo tecnológico, é o de baixo conteúdo, seguido pelo segmento médio baixo, mas com um resultado consideravelmente menor. O IEDI (2009) aponta que os subsetores alimentos, bebidas e tabaco, foram responsáveis sozinhos por $78,8 \%$ do saldo gerado pelo setor em 2008.

TABELA 4 - BALANÇA COMERCIAL DA INDÚSTRIA DE TRANSFORMAÇÃO EM US\$ BI.

\begin{tabular}{l|r|r|r|r|r|r}
\hline & \multicolumn{1}{|c|}{$\mathbf{2 0 0 3}$} & \multicolumn{1}{c}{$\mathbf{2 0 0 4}$} & \multicolumn{1}{c}{$\mathbf{2 0 0 5}$} & \multicolumn{1}{c}{$\mathbf{2 0 0 6}$} & \multicolumn{1}{c}{$\mathbf{2 0 0 7}$} & \multicolumn{1}{c}{$\mathbf{2 0 0 8}$} \\
\hline Baixa & 19.856 & 25.197 & 28.727 & 31.927 & 34.761 & 39.559 \\
Média-baixa & 5.488 & 8.871 & 10.258 & 10.545 & 9.185 & 5.118 \\
Média-alta & -3.376 & -2.531 & 443 & -897 & -10.344 & -30.190 \\
Alta & -5.245 & -7.484 & -8.320 & -11.779 & -14.824 & -21.653 \\
Prods. Ind. transformação & 16.723 & 24.053 & 31.107 & 29.796 & 18.779 & -7.166 \\
\hline
\end{tabular}
FONTE: IEDI (2009).

Pelo lado dos setores deficitários, alta e média alta intensidade tecnológica, os dois vêm apresentando saldos comerciais negativos ou muito próximos a zero durante todos os períodos analisados. Chama atenção o montante do déficit gerado pelo segmento de média alta intensidade (US\$ -30,2 bilhões em 2008). Por fim, o segmento de alta tecnologia, em 2008, atingiu um déficit de US $\$-21,7$ bilhões.

No que diz respeito ao saldo comercial brasileiro gerado pela indústria de transformação, este, que apresentou uma trajetória claramente ascendente entre os anos de 2003 e 2005, tal como indica o gráfico 2, em 2006 essa trajetória foi revertida e, em 2008 o déficit deste setor foi de US\$7,2 bilhões.

Cabe notar que houve uma queda substancial do resultado externo determinada pelo desempenho negativo da indústria de transformação, destacando-se que o último déficit registrado pelo setor tinha sido em 2001.

\footnotetext{
${ }^{5}$ Para isso, o IEDI (2009) utilizou certas categorias de agregações por intensidade tecnológica da indústria de transformação. O critério de conteúdo tecnológico segundo a OCDE discrimina os setores de alta, média-alta, média-baixa e baixa intensidade tecnológica.
} 




FONTE: IEDI (2009).

A este respeito, a conclusão é que o Brasil permanece, portanto, dependente, no que tange à geração de saldos comerciais dentro da indústria de transformação, de produtos com baixa e média baixa intensidade tecnológica. Enquanto os setores de alta e média alta tecnologia são grandes importadores e os maiores geradores de déficits. Além disso, é preciso considerar que após diversos anos de importantes superávits a indústria de transformação volta a gerar um déficit significativo. Além da concentração do saldo comercial do país em bens pouco industrializados, existe também uma concentração das exportações em bens de baixa tecnologia e das importações em produtos com alta intensidade tecnológica.

\section{CONCLUSÃO: DESINDUSTRIALIZAÇÃO E/OU REESPECIALIZAÇÃO PRODUTIVA}

A análise dos efeitos do nível da taxa de câmbio sobre as mudanças na estrutura da indústria de transformação mostra que a forte queda da participação do valor adicionado industrial no PIB brasileiro pode ser explicada pela tendência de apreciação real do câmbio, entre 1980 e 1993. Este fato deve, porém, ser mais bem qualificado com respeito às especificidades da estrutura industrial pré-liberalização. As plantas então estabelecidas, sob as políticas econômicas e industriais associadas ao modelo de industrialização substitutiva de importações, as quais pressupunham um elevado grau de proteção inerente a esse tipo de estratégia de desenvolvimento. Todavia, sem ter completado seu processo de industrialização, 
o Brasil se reinsere no cenário internacional com fortes desvantagens competitivas em setores estratégicos como o intensivo em ciências e em tecnologia. Sujeito, no plano interno, a um ambiente macroeconômico adverso (taxas muito altas de juros, ausência de políticas industriais e setoriais consistentes, déficit em infra-estrutura de transportes, etc.), a reação do parque produtivo doméstico foi então nitidamente defensiva, orientando-se pela sobrevivência diante das incertezas crescentes.

Entre 1980 e 1996, a indústria de transformação tem reduzida em 50\% a sua participação no produto interno bruto. Um dos fatores principais dessa evolução foi a forte apreciação cambial iniciada no período pré-abertura. Mas a despeito da agenda liberalizante, essa perda não foi recuperada no período 1997-2008 quando a economia brasileira consolida sua adesão ao processo de globalização comercial e financeira. Pelo contrário, apesar da modernização das plantas, favorecida pela importação de bens de capital e dos elevados ganhos de produtividade, a indústria continuou perdendo participação relativa entre 2004 e 2008, precisamente quando a economia brasileira crescia a taxas mais altas. Pesquisas futuras são necessárias para detectar as razões econômicas por trás desse comportamento. A opção por trajetórias de acumulação intensiva pode ser parte importante da explicação, mas sobressai-se também o fato de que a indústria que sobreviveu à apreciação cambial é basicamente produtora de bens de mais baixo valor agregado.

Análises históricas e comparações internacionais mostram que as mudanças nas formas de inserção internacional são decisivas na reconfiguração da indústria e, mais amplamente, do próprio ambiente econômico doméstico. Afastando-se das concepções mais otimistas da tradição liberal-neoclássica, não há fundamento teórico nem empírico satisfatórios que possam corroborar as interpretações de que os processos de liberalização econômica são sempre portadores de benesses e de vantagens econômicas irrecusáveis. As experiências dos países asiáticos confirmam que o recurso a uma estratégia consistente de desenvolvimento com políticas industriais adequadas é uma condição necessária para que os desafios impostos pela concorrência internacional possam se converter em fatores propulsores do desenvolvimento das nações. A mera adesão a um ambiente externo de alta concorrência pode acarretar perdas em setores e ramos importantes da indústria nacional. Políticas pró-ativas de desenvolvimento industrial devem ser o recurso básico para o enfrentamento da concorrência externa e para a aquisição de vantagens competitivas dinâmicas. 


\section{REFERÊNCIAS}

ENCONTRO DA ANPEC SUL, 12., 2009, Maringá. Regime Cambial e mudança estrutural na indústria de transformação brasileira: novas evidências para o período (1994-2008).

ARAÚJO, E. Política cambial e crescimento econômico: teorias e evidências para os países em desenvolvimento e emergentes. Tese de doutorado, IE/UFRJ, Rio de Janeiro, 2009.

BRESSER-PEREIRA, L. C.. The Dutch disease and its neutralization: a Ricardian approach. Brazilian Journal of Political Economy, vol. 28, no 1 (109), pp. 47-71, January-

March/2008.

CORDEN, W. Max e NEARY, J. Peter. Booming Sector and De-Industrialisation in a Small Open Economy, The Economic Journal, Vol. 92, No. 368, pp. 825-848, 1982.

IBGE - Instituto Brasileiro de Geografia e Estatística. Pesquisa Industrial Anual (PIA), 2008.

IEDI - Instituto de Estudos para o Desenvolvimento Industrial. Os resultados de 2008 e os Primeiros impactos da crise sobre O comércio exterior brasileiro, 2009.

IPEADATA - Instituto de Pesquisa Econômica Aplicada. Disponível em: http://www.ipeadata.gov.br.

PAVITT, Keith. Sectoral Patterns of technical change: towards a taxonomy and a Theory. Research Policy, 13, p 343-373, 1984.

FÓRUM DE SP, 5, 2008. Taxa de Câmbio e Mudança Estrutural da Indústria Brasileira. 